\title{
Continuity in Education in The Implementation of The STEM Education for The Children of Preschool and Elementary School Age Modular Program
}

\author{
Sergey Averin ${ }^{1 *}$, Natalia Murodhodjaeva ${ }^{2}$, Marina Romanova $^{1}$, Yulia Serebrennikova ${ }^{1}$, and \\ Andrey V. Koptelov ${ }^{3}$ \\ ${ }^{1}$ Moscow City University, Institute of Educational Psychology and Pedagogy, Department of \\ Teaching Methods, Moscow, Russia \\ ${ }^{2}$ Moscow City University, Institute of Educational Psychology and Pedagogy, Department of \\ Pedagogy, Moscow, Russia \\ ${ }^{3}$ Sam Houston State University College of Education, Center for International Education, Huntsville, \\ United States
}

\begin{abstract}
The article reveals the potential of introducing the STEM Education for the Children of Preschool and Elementary School Age authorial program as a means of managing the continuity process in the modern educational organization. The specific continuity content at the level of educational modules of the program is shown along with the results of monitoring the effectiveness of system implementation of the program at educational establishments. The study has been aimed at the theoretical justification and empirical verification of the effectiveness of the STEM Education for the Children of Preschool and Elementary School Age modular program as one of the means for ensuring the continuity of the preschool and general elementary education levels. During the study, the methods of analysis, theoretical modeling, pedagogical diagnostics, and mathematical statistics (U-Mann-Whitney test) have been used. Studying the effectiveness of the STEM Education for the Children of Preschool and Elementary School Age program based on three years of testing in preschool education has allowed detecting positive dynamics of the indicators in the experimental group. Given the identified level of the development of intellectual operations, imagination, and social intelligence of the children involved in the program at kindergartens, the STEM education program has been developed for the elementary school, the modules of which are shown in this article
\end{abstract}

\section{Introduction}

Improving the educational process in the modernization of the education system and a quantum leap in the development of new technologies entailed the need of the society in

\footnotetext{
* Corresponding author: $\underline{\mathrm{s}-\text { averin@vdm.ru }}$
} 
socially active, independent, and creative people who would be able to unconventionally solve new problems and introduce new content into all spheres of life. Particular importance is attached to the preschool and general elementary levels of education, since in this period, the fundamental basis of the child's personality is formed. The modern educational process shifts the focus to the development of the child's personality in all its diversity: curiosity, determination, independence, responsibility, creativity, ensuring social competence, and cognitive activity. Starting from elementary school age, the formation of the interest to learning and developing the motivation for independent knowledge acquisition as a separate educational goal comes to the fore [1-4]. In recent years, several publications devoted to this topic have noted that within the main educational program, the school cannot always achieve this goal to the full extent, since in the format of the class-and-lesson system, the children's ability to customize the educational environment for themselves and to be an active subject of the educational process is limited [5-8]. In this regard, the Federal State Educational Standard for General elementary education (hereinafter referred to as the EGE FSES [9]) envisages the mandatory availability of extracurricular activities, which not only contribute to the development of pupils' abilities to solve problems independently, but also allow them to act at the metasubject level, use knowledge more efficiently, and quickly master the research, constructive, design, and other skills. The solution of the above problems may be achieved through the introduction into the educational process of innovative partial programs aimed at developing the personality of the child and creating successive programs for preschool and elementary levels of education. The STEM Education for the Children of Preschool and Elementary School Age partial modular program (the authors - T. V. Volosovets, V. A. Markova, and S. A. Averin; the authors of educational modules for the level of general elementary education - S. A. Averin, N. S. Murodhodjaeva, M. A. Romanova, Y. A. Serebrennikova et al.) possesses the above qualities to the fullest extent [10]. The program was tested in stages. For three years (late 2017 through early 2020), the program was tested at 294 preschool educational institutions of the Russian Federation. The effectiveness of implementing the STEM Education for the Children of Preschool and Elementary School Age partial modular program was monitored in $2019-2020$ at the educational institutions of the Krasnodar Territory (N. V. Kabanova, F. I. Vakhovsky, T. A. Trifonova) under the scientific supervision of the authors of the program - V. A. Markova and S. A. Averin. Four hundred and twenty eight children were involved in the experiment; 182 of them were 3 to 5 years old, and 246 were of senior preschool age (5 to 7 years) [11]. The study was aimed not only at identifying the effectiveness of the program, but also at adjusting the content of the modules for elementary school so that they ensured the continuity of the two levels of education.

\section{Methods}

At the level of general elementary education, the program is aimed at revealing the intellectual and creative potential of the child's personality through mastering new competencies and forming the need for their independent and creative implementation. The program creates conditions for personal fulfillment in various activities. Additionally, the goals include the introduction to the competencies of the 21 st century and the formation of initial skills for solving practical problems in modern science, technology, and digital technology [12]. An effective means of developing intelligence, forming the motivation to learn, and developing creativity is scientific and technical creativity [7, 13-17].

A unique feature of the program for general elementary education is that it can be effectively mastered both by children who have not studied STEM before and by the children who studied at the preschool level through the STEM education program. This was originally envisaged by the authors of the program and is now provided by the variability of the content 
and the object-spatial environment, multilevel tasks, and various recommended forms, means, and methods of the program implementation.

The continuity of the educational modules of the program is systemic. For instance, Friedrich Fröbel's Didactic System educational module, which forms the basis of STEM education at the preschool level, is continued in the Engineering, Logic and Combinatorics, and Robotics and Artificial Intelligence modules of the program for the level of general elementary education.

The Lego-Design educational module, which creates the conditions for developing not only the design skills of preschoolers but also for familiarizing themselves with the basic physical concepts and for understanding the causal relationships, correlates with the Engineering module at the general elementary education level. The content of the Engineering module is aimed at improving the above competencies and provides the next step in the development of engineering thinking during the mastery of the Volumetric Design, 3D Modeling, and Design sections [18].

The Experimenting with Animate and Inanimate Nature educational module of the preschool level of the program allows maintaining the natural curiosity of children, developing the skills of independent research, collecting and analyzing the information, performing experimental work, and substantiating the conclusions of the research. Developed research abilities of children not only become the key to the successful completion of all the modules of the STEM education program but also ensure achievements in the educational subjects. At the same time, the Experimenting with Animate and Inanimate Nature educational module is directly continued in the Research Activities educational module of general elementary education, which ensures the formation of research abilities in children, such as the ability to see problems, ask various types of questions, formulate a hypothesis, define concepts, classify, collect and analyze information from various sources, observe, perform an experiment, draw conclusions and discourses, and substantiate the results of the study.

The Robotics educational module for the preschool level of the program is directly related to the Robotics and Artificial Intelligence educational module for general elementary education level. The names of the modules reflect the above-mentioned unique characteristic of the program, namely, continuity, while maintaining the full possibility of mastering the educational module even without the previous stage. In this educational module, this opportunity is mainly provided by two lines of robotics designers with different complexity levels (both in terms of assembly and in terms of programming), which allow building individual paths for achieving the educational goals of the module: the stage-by-stage progress from simple to complex tasks, or from complex tasks to the tasks of increased complexity [19].

The Mathematical Development educational module, which allows forming the key mathematical concepts and elementary mathematical representations for STEM education in the minds of preschool children, is continued in the Logic and Combinatorics educational module. The content of the Logic and Combinatorics educational module expands and concretizes the semantic lines of the elementary course in mathematics. Certain practical works may be used by the teacher at various stages of the educational process: when studying a mathematical concept, consolidating the studied material, or organizing homework of the pupils.

The YA SOZDAYU MIR (I CREATE THE WORLD) Cartoon Studio educational module at the level of elementary education is expanding meaningfully in the "Information and Media Technologies" educational module. At the preschool level of education, the Cartoon Studio is primarily a modern didactic tool for cognitive, speech, social, communicative, and artistic and aesthetic development of the children. The cartoon is not the end in itself; the processes of composing and interaction in the creation process, etc. are 
important. At the general elementary education level, while maintaining the above approach, the emphasis is added to learning various animation techniques, to forming information literacy and social competence, and to the introduction to the world of new professional areas: elements of blogging, media studies, etc. [13].

The key features of the program also include the following: variability of the forms, means, and content of the program; the development-oriented object-spatial environment as the "fourth subject" of the educational process; and the context of developing the professional competence of the teacher.

\section{Results}

To process empirical data, the methods of mathematical statistics were used (STATISTICA 10.0), and the criteria of $\chi 2$ Pearson and U-Mann-Whitney tests were applied. Based on the statistical analysis with the use of the nonparametric U-Mann-Whitney criterion at the $p \leq 0.05$ significance level, it was confirmed that the differences in the studied qualities for the age groups of $3-5$ years (the sample size was 182 children in the experimental group and 182 children in the reference group) and $5-7$ years (the sample size was 246 children in the experimental group and 246 children in the reference group) at the initial stage of the experiment were statistically insignificant, which indicated randomization of the choice of the experimental and the reference groups. Based on these data, an assumption was made that further changes in the studied qualities in the experimental group were ensured by the implementation of the STEM Education for the Children of Preschool and Elementary School Age partial modular program. At the intermediate stage with the significance level of $p \leq 0.05$ with the use of the nonparametric U-Mann-Whitney criterion, the statistically significant differences between the indicators of all the studied qualities of children $3-5$ and $5-7$ years old were confirmed in the experimental and the reference groups.

The statistical significance of the differences of each of the studied qualities for age groups of $3-5$ years and $5-7$ years in the reference and the experimental groups based on the $\chi 2$ Pearson criterion is shown in Tables 1 and 2, where the statistically significant differences are indicated by *. For instance, in the experimental group, all the differences were statistically significant.

Figures 1, 2, and 3 clearly show the dynamics of the profile of each studied quality for the age groups of $3-5$ years and $5-7$ years from the initial to the intermediate stage.

Table 1. Indicators of the studied qualities in the reference group

\begin{tabular}{|c|c|c|c|c|c|c|c|c|c|}
\hline \multirow{2}{*}{$\begin{array}{c}\text { The studied } \\
\text { qualities }\end{array}$} & \multirow{2}{*}{$\begin{array}{c}\text { The age of the } \\
\text { children }\end{array}$} & \multicolumn{3}{|c|}{ The initial stage } & \multicolumn{3}{|c|}{$\begin{array}{c}\text { The intermediate } \\
\text { stage }\end{array}$} & $\begin{array}{c}\text { The } \chi^{2} \\
\text { Pearson } \\
\text { criterion }\end{array}$ & $\begin{array}{c}\text { The level of } \\
\text { significance }\end{array}$ \\
\cline { 3 - 13 } & & low & medium & high & low & medium & high & \\
\hline \multirow{2}{*}{$\begin{array}{l}\text { Intelligent } \\
\text { operations }\end{array}$} & $3-5$ years & 101 & 64 & 17 & 87 & 71 & 24 & 1.84 & 0.66 \\
\hline & $5-7$ years & 82 & 134 & 30 & 67 & 138 & 41 & 0.17 & 0.79 \\
\hline Imagination & $3-5$ years & 98 & 77 & 7 & 84 & 86 & 12 & 0.19 & 0.67 \\
\cline { 2 - 12 } & $5-7$ years & 71 & 153 & 22 & 63 & 156 & 27 & 0.21 & 0.72 \\
\hline Social intelligence & $3-5$ years & 91 & 80 & 11 & 74 & 90 & 18 & 0.93 & 0.77 \\
\cline { 2 - 11 } & $5-7$ years & 76 & 143 & 27 & 58 & 156 & 32 & 0.84 & 0.66 \\
\hline
\end{tabular}


Table 2. Indicators of the studied qualities in the experimental group

\begin{tabular}{|c|c|c|c|c|c|c|c|c|c|}
\hline \multirow{2}{*}{$\begin{array}{c}\text { The studied } \\
\text { qualities }\end{array}$} & \multirow{2}{*}{$\begin{array}{l}\text { The age of the } \\
\text { children }\end{array}$} & \multicolumn{3}{|c|}{ The initial stage } & \multicolumn{3}{|c|}{ The intermediate stage } & \multirow{2}{*}{$\begin{array}{l}\text { The } \chi^{2} \\
\text { Pearson } \\
\text { criterion }\end{array}$} & \multirow{2}{*}{$\begin{array}{l}\text { The level of } \\
\text { significance }\end{array}$} \\
\hline & & low & medium & high & low & medium & high & & \\
\hline \multirow{2}{*}{$\begin{array}{l}\text { Intelligent } \\
\text { operations }\end{array}$} & $3-5$ years & 94 & 71 & 17 & 42 & 103 & 37 & 31.61 & $\mathrm{p}<0.0001$ \\
\hline & $5-7$ years & 84 & 128 & 34 & 12 & 135 & 99 & 48.32 & $\mathrm{p}<0.0001$ \\
\hline \multirow[t]{2}{*}{ Imagination } & $3-5$ years & 101 & 74 & 7 & 42 & 109 & 31 & 39.55 & $p<0.0001$ \\
\hline & $5-7$ years & 69 & 158 & 19 & 14 & 191 & 41 & 18.34 & $p<0.0001$ \\
\hline \multirow{2}{*}{$\begin{array}{c}\text { Social } \\
\text { intelligence }\end{array}$} & $3-5$ years & 87 & 82 & 13 & 59 & 91 & 32 & 35.12 & $\mathrm{p}<0.0001$ \\
\hline & $5-7$ years & 80 & 145 & 21 & 32 & 130 & 84 & 36.15 & $p<0.0001$ \\
\hline
\end{tabular}
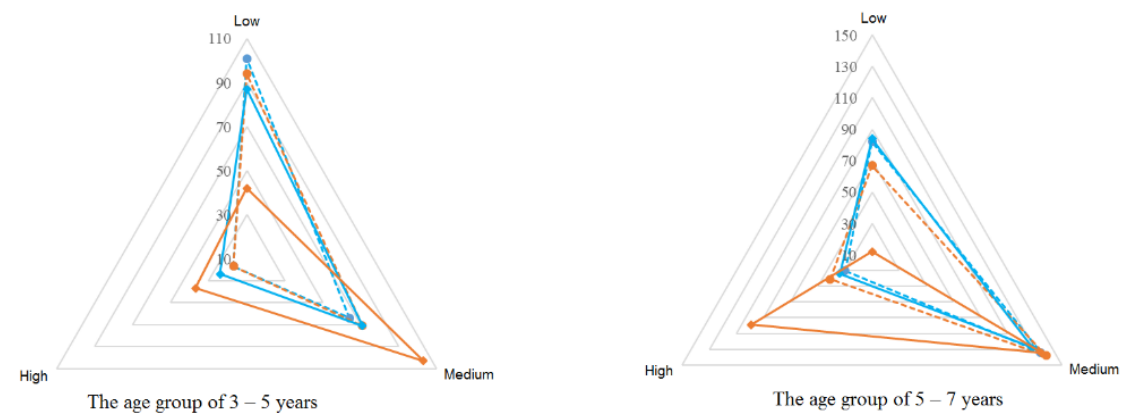

Fig. 1. The development of the intellectual operations profile
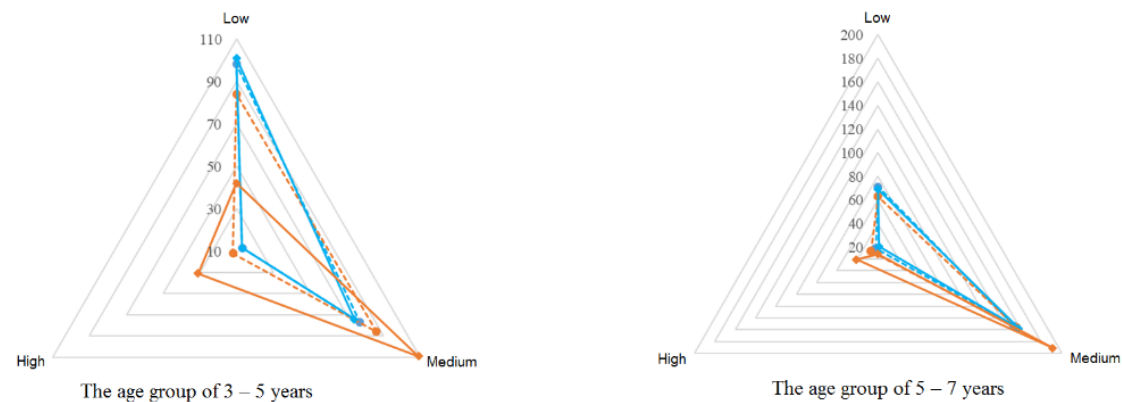

The age group of $3-5$ years

The age group of $5-7$ years

Fig. 2. The development of the imagination profile 


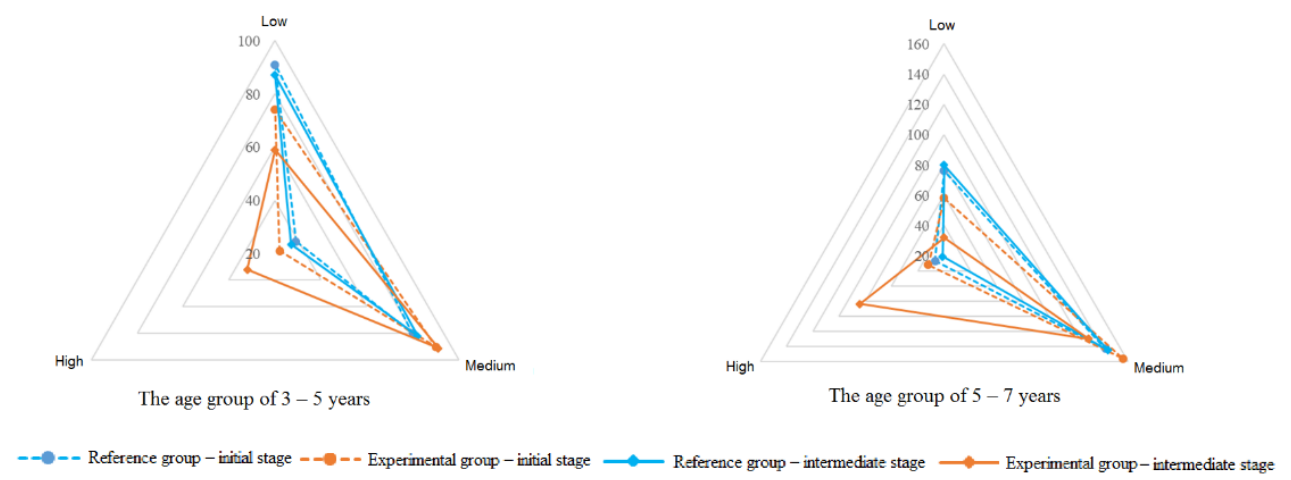

Fig. 3. The development of the social intelligence profile

\section{Discussion}

Implementation of all program modules involves the use of individual, subgroup, and group forms of pupils' work organization. With that, subgroup and group forms are usually used in the joint scientific and technical creativity process: assembling and programming robots, creating authorial cartoons in various techniques, blogging or making children's television programs, etc. This puts children in a situation where such qualities as sociability, ability to hear each other and listen to each other, to respect the position of the others, and to assume responsibility for common work are naturally formed $[12,20]$. At the same time, working with each educational module involves expanding the forms of a child's social interaction in various situations: substantiation of research results, participation in the contests and festivals in robotics and mathematics, presentation of design work, presentation of authorial cartoons at festivals, etc., which contributes to the development of the child's emotional intelligence and social competence.

\section{Conclusion}

The transition from the knowledge paradigm to the competency one has been postulated in pedagogical theory for several decades. At the same time, the realities of school education (the class-and-lesson system, the unified state exams, etc.) put teachers in a situation of forced dominance of the reproductive methods, the priority of learning. However, it is obvious that information is being updated at a tremendous speed today, and living in the modern world, the child also needs an effective adaptation tool: the ability to process information and to think critically, flexibly, creatively, etc. The EGE FSES emphasizes the role of extracurricular activities in the formation of the above competencies. The program allows building this process based on the principles of continuity, support for the child's creative initiative, and systematicity.

One of the key characteristics of the STEM Education for the Children of Preschool and Elementary School Age program is facilitating the formation of the personality of the Creator, while saturation of the modern world with technical means with intuitive interfaces and a wide selection of goods create the context for the formation of the consumer, which may have a detrimental effect on the economy and ecology of the future. In this regard, the STEM Education for the Children of Preschool and Elementary School Age program not only performs the function of the personality development in each child but also forms the mindset of the new generation. In mastering the program, children develop intelligence, research 
abilities, and creativity in the process of joint scientific and technical creativity, which involves the creation, substantiation (or presentation), and finalization (development) of a new product.

\section{References}

1. M. Fleer, Learn. Culture and Soc. Interaction 24, 100355 (2020)

2. J. McFadden, G. Roehrig, Disciplinary Interdisciplinary Sci. Educ. Res. 2(4), (2020)

3. T. Miller, Int. J. STEM-Educ. 5(39), (2018)

4. C. Ringstaff, J.H. Sandholz, From Budget to Bus Schedules: Contextual Barriers and Supports for Science Instruction in Elementary schools, In: S.M. Uzzo, S.B. Graves, E. Shay, M. Harford, R. Thompson. (eds). Pedagogical Content Knowledge in STEM. Research to Practice (Springer International Publishing) 4, 67-82 2018.

5. M. A. Romanova, Innov. Educ. 2, 113-125 (2011)

6. Yu. A. Serebrennikova, Teacher training for the implementation of STEM education. Proceedings of the international round table «Management solutions to pressing problems of modern education» (Moscow, 2019)

7. I.I. Gökçen, E. Ahmetoğlu, The Friedrich Froebel Approach, Recent researches in Education (Cambridge Scholars Publishing - Ch. 23, 2018, 355-366)

8. A. Savenkov, S.I. Karpova, E.I. Sukhova, Psy. (Savannah, Ga.) 55(2), 74-84 (2018).

9. Order of the Ministry of Education and Science of Russia dated 06.10.2009 N 373 (as amended on December 31, 2015) "On the approval and enactment of the Federal State Educational Standard in Elementary General Education".

10. T. V. Volosovets, V. A. Markova, S. A. Averin, STEM education for children of preschool and primary school age. Partial modular program for the development of intellectual abilities (BINOM, Laboratory of knowledge, Moscow, 2019)

11. F. I. Vakhovsky, N. V. Kabanova, V. A. Markova, T. A. Trifonova, STEM education of preschool and primary school children: Report on the implementation of a partial modular program for the development of intellectual abilities in the process of cognitive activity and involvement in scientific and technical creativity in educational organizations of the Krasnodar Territory (OLMA-PRESS, Krasnodar, 2020)

12. K. Dreessen, S. Chepers, Int. J. Child-Comp. Interaction 20 35-42 (2019)

13. N. S. Murodhodjaeva, V. N. Punchik, I. V. Amochaeva. Cartoon Studio educational module "I CREATE THE WORLD" (BINOM, Laboratory of knowledge, Moscow, 2019)

14. A. Hafșa, A. C. Safaningrum, F. Fadhilaturrahmi, V. Min, C. L. Y. Ling, Int. J. STEM Educ. 7(11) (2020)

15. A. MacDonald, L. Danaia, S. Murphy, STEM Education Across the Learning Continuum. Early Childhood to Senior Secondary (Singapore, Springer, 2020)

16. G. Mantzanidou, Educational Robotics in Kindergarten, a Case Study. In: M. Merdan, W. Lepuschitz, G. Koppensteiner, R. Balogh, D. Obdržálek. (eds). Robotics in Education. RiE 2019. Advances in Intelligent Systems and Computing. (Springer, Cham - Vol 1023, 2020)

17. K.C. Margot, T. Kettler, Int. J. STEM Educ. 6(2) (2019)

18. M. Lau, S. Multani, Engineering STEM Teacher Learning: Using a Museum-Based Field Experience to Foster STEM Teachers' Pedagogical Content Knowledge for 
Engineering. In: S.M. Uzzo, S.B. Graves, E. Shay, M. Harford, R. Thompson. (eds). Pedagogical Content Knowledge in STEM. Research to Practice (Springer International Publishing. Ch.11. 2018, 195-213)

19. N.F. Tolksdorf, S. Siebert, I. Zorn, L. Horwath, K.J. Rohlfing, Int. J. Soc. Robot. (2020)

20. M. Fleer, When preschool girls engineer: Future imaginings of being and becoming an engineer, Learn. Culture and Soc. Interaction (in press). Available at: https://www.sciencedirect.com/science/article/abs/pii/S2210656119303162 